\title{
History and Reason: The Three Historiographic Paradigms Extracted by Kuhn from Three Scientific Theories
}

\author{
Pietro Cerreta ${ }^{1}$, Antonino Drago ${ }^{2}$ \\ ${ }^{1}$ Associazione Scienza Viva, Calitri, Italy \\ ${ }^{2}$ Formerly at University of Naples, Naples, Italy \\ Email:p.cerreta13@gmail.com,drago@unina.it
}

Received 8 March 2016; accepted 27 June 2016; published 30 June 2016

Copyright (C) 2016 by authors and Scientific Research Publishing Inc.

This work is licensed under the Creative Commons Attribution International License (CC BY). http://creativecommons.org/licenses/by/4.0/

(c) $\underset{\mathrm{EY}}{\mathrm{i}}$ Open Access

\section{Abstract}

The old historiography considered only cumulative, positive scientific results. Koyré's one instead took into account both successes and errors of scientists in the context of their culture. In 1962, Kuhn introduced a completely new conception of the scientific events based on a ceaseless succession of paradigms and revolutions. The success of his book, The structure of scientific revolutions, was immediate. But more than the "revolution" cited in title of the book, his main concept was the "paradigm", which is the set of the concepts ruling the scientific practice of a given community. Although largely accepted, Kuhn's scheme was not spared by criticisms, also from scholars favorable to it. Therefore, throughout his life he was forced to reassess it several times, although never stopping to consider it valid, even when he renounced to apply it to the study of the birth of quanta. In this work, he opposed to the revolution of quanta that previous historians fixed in the years 1900-01, a sort of continuity between the Boltzmann's classical concepts and the Planck's mathematics. The debate on Kuhn's historiographic ideas has been wide and rich in intellectual stimuli. Actually, he took advantage of those stimuli to develop a better definition of his system. Towards the end of his life, with the aim to give a final version to his original scheme, he went back to consider a parallelism between the history of science and the biological evolutionism, already introduced in SSR. The present paper is aimed at analyzing these Kuhn's suggestions on the methodology of history of science; we will provide an interpretive framework linking each of his different historiographical suggestion with a specific scientific theory; i.e. respectively, the Newtonian mechanics, the thermodynamics and the Darwinian theory of evolution. In other words, we wanted to show that Kuhn always made use of historical categories corresponding to the basic notions of a particular scientific theory. 


\section{Keywords}

\section{Historical Paradigms, Historiographic Paradigms, Parallelisms, Revolutions, Continuity}

\section{Three Historiographic Schools ${ }^{1}$}

In history of science a change of the greatest importance occurred in the middle of the last century. A "new historiography” born through such historians as Alexander Koyré, Thomas Kuhn, Imre Lakatos and others.

Retrospectively, it was possible to pinpoint three main schools in the evolution of the historiography of science after it was emancipated from a priori philosophical views: the positivistic one which dominated the historians' minds until the first decades of the $20^{\text {th }}$ century, Koyré's one which began in the Thirties, and finally, Kuhn's interpretative scheme of The Structure of Scientific Revolutions (hereafter, SSR) (Kuhn, 1962), which began in the Sixties ${ }^{2}$. These three schools had a great impact on the following generations of scholars and produced a large number of specific studies.

As a starting point for our discussion, we would like to summarize the three historiographies by means of some characteristic features (Table 1), i.e. the conception of the history of science, the vision on the science (and on scientists) and the specific task attributed to historians. These features, in our opinion, are able to identify better than others the essential nature of the historiographic paradigms under consideration (De Regt, 1996).

The positivistic historiography is titled also as "the old historiography" since it is the oldest one which rejected a priori philosophical interpretations of the history of science; it still works as the reference kind of history to those historians who refuse any invasion from philosophers. According to it, the role played by the historian is to find out which and how many relevant events occurred inside the scientific progress, and moreover to locate them chronologically. It was, therefore, a work of arranging together and updating in a rich catalogue both the inventions and the discoveries.

In the second row, we place Koyré's historiography, which was first presented in a series of Koyré's essays, collected in the book Galileian Studies of 1939 (Koyré, 1966). According to Koyré, the study of the errors occurring inside the development of science is as important as that of its successes. For this reason, even the false scientific theories must find room inside a historical presentation. This conception of the role of both science

Table 1. Three historiographic schools and their main features.

\begin{tabular}{|c|c|c|c|}
\hline Historiographic school & $\begin{array}{l}\text { Conception of history of } \\
\text { science }\end{array}$ & Picture of both science and scientists & Historians’ task \\
\hline $\begin{array}{l}\text { (Old) positivistic } \\
\text { Historiography }\end{array}$ & $\begin{array}{l}\text { History of the positive } \\
\text { scientific results; } \\
\text { determination of a } \\
\text { discover's date }\end{array}$ & $\begin{array}{l}\text { Science as a cumulative growth; } \\
\text { a great scientist as a point of } \\
\text { accumulation of a lot of results }\end{array}$ & $\begin{array}{l}\text { Ordering the cumulative } \\
\text { results, linearization } \\
\text { of the events }\end{array}$ \\
\hline KOYRE’ (1939) & $\begin{array}{l}\text { History of both results and } \\
\text { errors in the scientific } \\
\text { development }\end{array}$ & $\begin{array}{l}\text { Each scientist is placed within } \\
\text { both the culture of his time and } \\
\text { the scientific context }\end{array}$ & $\begin{array}{l}\text { Recognition of both scientific } \\
\text { and philosophical factors of } \\
\text { the historical change }\end{array}$ \\
\hline $\begin{array}{l}\text { KUHN (1962) } \\
\text { (SSR) }\end{array}$ & $\begin{array}{l}\text { History of science structured } \\
\text { by revolutions }\end{array}$ & $\begin{array}{c}\text { Scientists' community, } \\
\text { normal science, paradigm, anomaly, } \\
\text { incommensurability, revolution }\end{array}$ & $\begin{array}{l}\text { Recognition of the paradigms } \\
\text { severed by revolutions }\end{array}$ \\
\hline
\end{tabular}

${ }^{1}$ For a review on the notion of historiography and its main features see: Kokowski (2006).

${ }^{2}$ This was the first of Kuhn's works that presented some general interpretative notions which are immanent in the history of science but include also philosophical contents. Although written after his celebrated The Copernican Revolution, (Kuhn, 1957), SSR did not intend to be the generalization of the concepts outlined by this book. In fact Kuhn, referring to this one, affirmed that "The extent to which heliocentrism was more than a strictly astronomical issue is a major theme of the entire book" and not other (see T. S. Kuhn, SSR, op. cit. p. 149, note 4). So, it is true that Kuhn in SSR employed some examples of the Copernican Revolution, but followed a completely different interpretive scheme. About the Copernican revolution as illustrated by Kuhn see Kokowski appraisal: “Kuhn’s book... is a popular book on the level of laymen, not a professional monograph on the topic.” (Kokowski, op. cit., p. 860). 
and scientists is very different from the positivistic one. Indeed, according to Koyré (Cerreta, 1994), in science development there are no precursors, because the work of each scientist is not finalized to the conclusion of a historical project transcending it, but is just related to the period in which it is carried out.

Therefore, science historians are not hagiographers of those scientists who played decisive roles inside the history of science, but researchers of the most important factors explaining the historical change in the period of their lives. For this reason the main task to be accomplished by a historian is to relate the lot of historical events to the essential factors of change. For instance, Koyré is proud of having related the history of $17^{\text {th }}$ Century scientific revolution to two factors: "the geometrization of space and the destruction of cosmos". Notice that for the first time these factors introduced in the historiography some interpretative categories which are first of all scientific in nature and yet are open to a philosophical view. They are scientific in nature because referring to both the most ancient scientific theory, Euclid's Geometry, and to each kind of mathematics used for representing space, which, according to Descartes and most following scientists, is the basic notion of theoretical physics. They are also philosophical in nature because referring to both the intellectual overcoming the ancient Greek limitation to the finite only, and the philosophically correct application of mathematics to the nature $^{3}$.

In the third row "Kuhn's historiography” refers mainly to SSR, i.e. the book which successfully presented an entirely new interpretative scheme. In SSR Kuhn illustrates the idea that is quite apart from the positivistic conception of science history: scientific results are not cumulative in nature; the historical development of science is rather fashioned by some events which are of a revolutionary nature. Moreover, his historical conception is different from Koyré's one too, although he declares he was influenced by Koyré's ideas ${ }^{4}$. Kuhn provides the idea of historiography as a general theory of the revolutions occurred in the whole history of science. His historiography relies upon a system interconnecting the following notions: scientific community, normal science, paradigm, anomaly, revolution and incommensurability. Despite some problems and failures, this interpretative scheme still leads the research of several historians and philosophers of science.

\section{The Paradox of the New Historiography: The Enormous Success of Kuhn's SSR}

Before Kuhn's SSR, books of history of science were restricted to a niche of specialists in this branch. Instead, SSR gained an extraordinary audience. It was translated into 19 languages and sold more than a million copies.

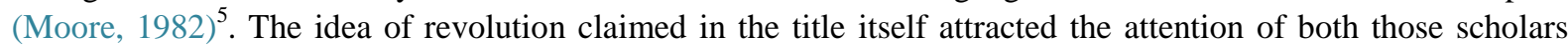
who hoped to see a change in the perception of science, that was no more stiffly characterised by rigid features according to Kuhn (mathematics first), and those laymen wanting to confirm their revolutionary views from the political realm to the scientific realm. So the term "paradigm", the main concept of SSR, was able to gain notoriety, not only among historians of physics but also among the ones of all scientific cultures and even the common people.

Yet, just after SSR publication, Kuhn's appraisal of the history of Physics was drastically contested. It was apparent to several critics that the notion of Gestalt, so crucial in determining the modality of the historical change between two subsequent paradigms, could occur in the mind of a single scientist, not surely in the collective mind of the scientific community, usually extended worldwide.

Moreover, one year after SSR's edition, Margareth Mastermann pointed out the inaccuracy of Kuhn's concept of "paradigm". This one, determining the period of time of the "normal science", proves variable according to its context, thus getting around twenty different meanings; hence it reveals itself as an ill-defined notion (Mastermann, 1970: pp. 59-89). Consequently, also the notion of revolution is ambiguous, so that all basic notions of Kuhn's framework are uncertain.

The notion of "scientific community" is one of Kuhn's most important notions since it experiences the paradigm and the normal science. Kuhn defines the scientific community as a group of scientists who share the same paradigm; in its turn, a paradigm is a collection of already known scientific achievements and pre-suppositions, which address the activity of a scientific community; again, in its turn, this activity is defined as the normal sci-

\footnotetext{
${ }^{3}$ For a detailed analysis of Koyré historiography, see (Drago, 1994, 2016).

${ }^{4}$ (Kuhn, 1970c) p. vi fn. 1, pp. 1-3. For a sketchy summary of his basic historiographic ideas see (Corry, 1993).

${ }^{5}$ Moore (1982).
} 
ence of the community. Therefore, as stressed by Mastermann ${ }^{6}$, the scientific community shares a set of scientific achievements that address the activity itself (Masterman, 1970). In sum, it can be noted that there is a conceptual circularity underlying the definitions of Kuhn's historiographic notions.

A recent analysis of Kuhn's notion of revolution independently confirms this appraisal. First, even in political sciences, the notion of revolution does not receive a neat definition; indeed four schools of interpretations of this notion occurred in the last century and at present the notion is even more troubled by the last revolutions of a non-violent kind (Drago, 2010; Chenoweth \& Stephen, 2011). Second, a paper lists four criticisms to Kuhn's notion of scientific revolutions:

I argue that the sorts of events Kuhn regards as scientific revolutions are a diverse lot, differing in significant ways (Wray, 2007).

However, the author wants to find a remedy for that. He expresses some criteria which Kuhn implicitly suggested. Nevertheless the better instance he suggests for his new definition of scientific revolution is the historical "change in early modern astronomy"; yet, in our opinion this historical change belongs to a too wide context to offer a certain definition of revolution.

On the other hand, so many radical ambiguities did not prevent the above two critics from supporting Kuhn's historiographic scheme. Only Caneva is disillused by Kuhn's works; he performs a systematic analysis of all their "anomalies and inconsistencies", without seeing a possible remedy to the different "Kuhns" appearing from these works (Caneva, 2000). What is surprising in this case is the long period of time (thirty years) for achieving an accurate analysis of these works.

Furthermore, two decades after SSR, this scheme was missed by Kuhn himself in illustrating the crucial historical case of the quanta revolution, notwithstanding that he performed an impressively detailed analysis of the relevant events. This lack was immediately and blatantly remarked. Some scholars questioned this illustration by ironically speaking of a "paradigm lost” (i.e. a paraphrase of Milton's poem, "Paradise lost") (Klein et al., 1979; Kuhn, 1984; Kuhn, 1980). Yet, the question why Kuhn missed it remained without a satisfactory answer.

Consequently, the following questions are unavoidable. Why the common reader did not remark this essential ambiguity in Kuhn's notions, even after the scholars' criticisms? Why stressing Kuhn's ambiguities in the notion of respectively "paradigm" and "revolution" did not prevent both Mastermann and Wray to remain supporters of Kuhn's historiographic scheme? Why Kuhn failed the application of his famous interpretation to quanta revolution? These questions require answers that overcome a mere meditative reading of SSR; they have to take into account not only the technical features of Kuhn's history of science, but also the philosophical view SSR implicitly represents.

This kind of search is the main topic of a recent paper whose title immediately refers to this wider realm:

The claim of this paper is that Kuhn inadvertently allowed features of his procedure and experience of as an historian to pass over into his general account of science... Kuhn's familiar claims... now appear as methodological commitments rather than historico-philosophical theses (Larvor, 2003).

This appraisal gives reasons for a very long period of harsh discussions on Kuhn's SSR without obtaining a conclusive result. In other words, the implicit part of Kuhn's account is much more important than the explicit part, including his ambiguous historico-philosophical notions of paradigm, revolution, abrupt historical change, etc.

In sum, despite its intrinsic weaknesses, since its apparition Kuhn's interpretation obtained the scholars' consensus which previous facts show to be gained by means of not completely rational reasons. We think, therefore, that its concepts have been supported by a commonly shared paradigmatic attitude which is our task to make apparent.

In order to take this implicit part into account, hereinafter we will outline a new interpretation of Kuhn's SSR, so radical that it risks to be a rough appraisal. In the previous author's words, we will interpret SSR's illustration as an implicit reference to "methodological commitments" to a basic paradigm in the scientific culture, that is

\footnotetext{
${ }^{6}$ As stressed by M. Mastermann in (Mastermann, 1970): “There is clearly a circularity here: first we define a paradigm as an already finished achievement; and then, from another point of view, describe the achievement as bulding up a round some ready existent paradigm”.
} 
the Newtonian paradigm, which is the same paradigm dominating the scientific research of the long period of time considered by Kuhn's SSR, the period of classical physics. In short, our thesis is that SSR unwarily translated the basic notions of the dominant paradigm of his case-study in notions representing methodological categories of history of science. In other words, Newtonian categories have been translated into historicopolitical notions by him (e.g. revolution), which of course attracted a lot of non-physicists and non-scientific readers. The result, representing a basic cultural paradigm, of course appeared as irrefutable by most scholars.

\section{A Surprising Coincidence}

As first step of our comparison, it should be noted that (Gernand and Reedy, 1986) demonstrated that Kuhn's scheme parallels that of Planck's philosophical writings (Table 2).

An even more relevant fact is that Planck's writings have not been read by Kuhn before publishing SSR (Gernand \& Reedy, 1986: p. 474). Therefore, one is led to think that physicists, when retrospectively pondering upon the revolutions inside the historical development of physics, spontaneously conceptualize the historical events by means of almost the same words ${ }^{7}$.

As a second step, let us remark not only the correspondences between the two notions on each line, but also the correspondence between the two lists of notions in the two columns; the left one summarizes dynamics stressed by SSR and the right one reiterates the same dynamics.

Moreover, Gernand and Reedy tell us that, besides Planck, not only Fleck-as Kuhn himself recalls (Kuhn, 1962: p. ix) —but also Dilthey (Gernand \& Reedy, 1986: pp. 472-473) described with a quite similar dynamics the historical development of science as Kuhn's and Planck's.

Therefore, it is possible to conclude that, rather than from the accuracy of his fundamental notions, the success of Kuhn's historiographic scheme derives from the strength of an unwarily assumed framework of interpretative categories that inform the minds of scholars reflecting upon the history of physics.

\section{The Scientific Nature of Kuhn's First Historiographic Paradigm: SSR and Newton's Mechanics}

As a third step, it should be noted that even more surprisingly two authoritative historians of science considered as very pertinent to the history of physics to translate the Newtonian paradigm of theoretical mechanics into historiographical categories. In 1983 Stephen Brush declared that this translation is a widespread custom among the historians:

Newtonian mechanics was a paradigm for most scientists during the greater part of the last two centuries and is therefore the paradigm of the paradigms for historians of science... one may recall that until around 1900 it was assumed that any problem in physics could be solved, at least "in principle”, by applying Newton's law of mechanics; it was only necessary determine forces and the mechanical properties of the parts of the system and then compute a solution for the appropriate set of differential equations. Since this was the most successful theory in any science, theorists [all other branches of sciences] tried to imitate it; but that meant adopting what was thought to be Newton's philosophy of nature as well as his scientific method.

Table 2. Comparison between the system of basic notions of Kuhn's historiography and that of Planck.

\begin{tabular}{cc}
\hline KUHN's SSR & PLANCK \\
\hline Paradigm & Weltbild (world-picture) \\
Normal Science & Scientists' typical activity \\
Anomaly & Facts which cannot be fitted into the existing theory \\
Incommensurability & Incompatible \\
Revolution & Profound reconstruction \\
\hline
\end{tabular}

$\overline{7}$ (Cerreta, 1994a; Cerreta, 1994b; Cerreta, 2002; Cerreta and Drago, 2004). 
If we think that the sciences have now rejected the Newtonian paradigm, we can nevertheless use this historical case to understand what it means to be dominated by a paradigm (Brush, 1983).

Independently, Ivor Grattan-Guinness suggested that a historian might follow this same translation of Newtonian notions in historiographic categories:

In other, more mathematical words, the historical space [of the history of science] is insufficiently defined. I use the word "space" deliberately, for I regard the historian as working in a space in a modern mathematician's sense: a multi-dimensional region, whose dimensions are determined by the historical and historiographic factors which he brings to his studies. Historical figures are like mass-points; influences between them are like forces of attraction and repulsion, and more general influences resemble fields. A community is thus a collection of mass-points, usually in some sort of equilibrium, but vulnerable to substantial disturbance. I find the analogy useful, although I not take it further and play Cauchy, for example, and try to set up the differential equations to represent the phenomenon. Cliometrics has not yet advanced so far (Grattan-Guinness, 1990).

Indeed, an accurate inspection of SSR shows that there exists a linkage between its basic notions and the system of concepts underlying Newton's mechanics.

At a first glance, two notions, i.e. paradigm and normal science, appear as mutually correlated notions, as well as anomaly and revolution. It is a paradigm, indeed, which determines the smooth and well-addressed trajectory of normal science for the history of scientific community and it is an anomaly that causes an abrupt trajectory's change.

Hence, Kuhn implicitly considers an anomaly as an a priori cause anyway it is generated, whereas a paradigm plays the role of the absence of disturbing causes. They cause the corresponding sociological effects, i.e. respectively revolution and normal science. In other words, science proceeds in a normal way as a consequence of a paradigm acting upon the scientific community; instead science radically changes when an anomaly challenges a traditional paradigm. In this way Kuhn introduces us to a general theory of Newtonian scientific behaviors, or better a historical dynamics of Newtonian kind. This historiographic theory appears to us as related to Newton's Mechanics according to the following table illustrates (Table 3).

According to this parallelism, it can be said that Kuhn's historiographic theory is fashioned by both notions of "mechanical kinematics"- whose two possible states are "normal science" and "revolution"—, and "dynamics", constituted by a sequence of "paradigms" and "anomalies". In other terms, these notions rule the kind of the scientific activity, either normal or revolutionary, in each of the two above-mentioned states.

In the above passage it has been recalled that Mastermann remarked a circularity between the two SSR's definitions of scientific community and normal science. In SSR, this circularity plays the same role played by the reference frame in Classical Mechanics. Indeed, after the rejection of the Newtonian absolute space, it is known that in Classical Mechanics the "law of inertia"-i.e. the motion of a body is a uniform one if no force acts upon it-holds true provided that the reference frame is an inertial frame. However, a reference frame is defined as inertial exactly when the motion of a body free of forces is a uniform one. Therefore, the definitions of "reference frame", "inertial motion" and "uniform motion" are, all together, circular.

In the end, we conclude that the notion of a scientific community in Kuhn's scheme represents a sociological

Table 3. Comparison between the system of basic notions of Kuhn's historiography and that of Newton's mechanics.

\begin{tabular}{cc}
\hline KUHN's SSR & NEWTON's MECHANICS \\
\hline Paradigm & Force $=0$ \\
Normal Science & Velocity $=$ const \\
Anomaly & Force $\neq 0$ \\
Incommensurability & $\mathrm{v} 2 \neq \mathrm{v} 1$ \\
Revolution & Acceleration \\
\hline
\end{tabular}


space where the scientific facts occur i.e. a sort of reference frame similar to that suggested by Grattan-Guinness's analogy above.

The parallelism between Kuhn's scheme and Newton's scheme goes further by comparing Kuhn's interpretative language and Newton's mathematical language (Cerreta \& Drago, 1991). In SSR all goes as if Kuhn considered the scientific activity, instantiated by a lot of historical case-studies, as resumed by a mathematical function $A(t, c)$, depending on both time " $t$ " and the scientific community " $c$ ". If in a particular historical period the scientific community is carrying on "normal science", Kuhn considers the time derivative of such a functioni.e. $A^{\prime}(t, c)$ - as a constant. Then he compares the time derivatives of $A(t, c)$ in adjacent periods; if these derivatives are the same, then the community follows the same normal science; if they are different, then between them there is a revolution, i.e. an exceptional event.

Since, according to Kuhn, the task of the historian is to search and discover the various paradigms succeeding one after another through revolutions (whose recurrence in time is for him a unquestionable point ${ }^{8}$ ), this task can be translated in the study of a mathematical change of the derivative of $A(t, c)$.

In opposition, the task of a positivistic historian is described by Kuhn as that of calculating the time integral of $A(t, c)$; that is, summing up the sequence of several contributions produced by the scientific activity in a given period of time. Of course, this sum hides the occurrence of revolutions, as textbooks usually do ${ }^{9}$.

It is to stress the exceptional nature of the cultural operation implicitly performed by Kuhn. Through his implicit translation, he actually rose some basic scientific notions up to historiographic categories ${ }^{10}$. For performing his cultural operation, Kuhn made use of a well-defined and consistent set of scientific notions, those defining scientific dynamics, like Classical Mechanics described it; such a set, suitably translated in historical categories, fashioned a specific concept of historical dynamics. In other terms, Kuhn hypostatised the paradigmatic character of the scientific notions of the Newtonian dynamics into historical categories describing temporal dynamics of science. That cultural operation substantiated the dream supported by Euler in the history of science, i.e. to substitute the old philosophical metaphysics for the new metaphysics regarding Newton's mechanics, because the latter was already verified by so many experimental instances (Cassirer, 1906). It should be further remarked that this cultural operation is self-referential; in order to describe the dominant role of the Newtonian paradigm for the whole period of classical science, Kuhn has made use of a historiographic scheme which is merely isomorphic to the Newtonian paradigm.

Moreover, it is to be remarked that Kuhn's SSR intended to introduce a great historiographic revolution. Indeed, when presenting his interpretative notions and categories, he avoided to stress any explicit continuity with Koyré's ones ${ }^{11}$, as he instead did with Fleck's ideas ${ }^{12}$ for example, although he claimed to consider Koyré his teacher $^{13}$. Actually, it is significant that SSR neglected even the particular revolution studied by Koyré, although this one played a crucial role in the history of science.

Indeed, in such a way Kuhn thought to have achieved a historiographical framework of a more general importance than Koyré's one. Whereas the latter explained the dynamics of only one, though highly important, scientific revolution, Kuhn thought to have offered a precise scheme for interpreting the whole sequence of revolutions in science.

\footnotetext{
${ }^{8}$ Paradoxically they may even be invisible! (Kuhn, 1962, chp. XI): “The invisible revolutions”.

${ }^{9}$ Ibidem, pp. 1-3, 136-137.

${ }^{10}$ However this operation has already been performed by Koyré, when he rose two scientific notions, i.e. both geometry and space, up to categories of his historiography. But Koyré did not change them in new historical terms; moreover, he did not link all of them into a structured system of historical notions. About the several ways for translating scientific categories into historical categories, see (Drago, 1996: pp. 159-167).

${ }^{11}$ In SSR ( p. v-vii), notwithstanding that Kuhn says he continued to study Koyré’s writings, his historiographic concepts of paradigm, normal science, anomaly, revolution (as a change for paradigms) and incommensurability don't refer specifically to the mentioned writings. And, while it is easy for us to recognize Kuhn's general tribute to Koyré, a clear connection of his conceptual scheme with the revolution outlined in A. Koyré, From the close word to the infinite universe, 1957, cannot be found. There it should be noted that Kuhn does not use "destruction of cosmos", nor the "geometrization of space" indicated by Koyré as fundamental categories at p. ix of the cited book. Probably he was afraid that by using the notion of infinite (which is present in the title and plays a fundamental role in Koyré's study of the $17^{\text {th }}$ century revolution), he would be forced to include mathematics into his interpretative scheme and hence to give a more precise definition of the paradigm.

${ }^{12}$ It is relevant that, speaking about Fleck, Kuhn tells precisely that many of his historiographical ideas have been anticipated by him in his essay: Entstehung und Entwicklung einer wissenschaftlichen Tatsache (Basel, 1935). When looking for an analogue declaration regarding a possible anticipation by Koyré, this cannot be found in SSR.

${ }^{13}$ Kuhn defines Alexander Koyré as his teacher. (Kuhn, 1977: pp. 21-30), [revised version of a paper presented in 1966].
} 
Kuhn's choice to hidden Koyré's contributions may be explained. After SRS he evaluated Koyré's studies as too confined to the scrutinizing of the texts (explication de texte). According to him, this work focuses the attention of the historian on only the scientific ideas and disregards the scientific equipments. Kuhn imagined even a "disaster" (Kuhn, 1970) of Koyré's methodology, if Koyré wanted to apply his textual inspection to studies of chemistry, electricity and magnetism since the end of the eighteenth century when the new crafts, instrumentation and technology, more than toward ideas, motivated scientists.

Moreover, it should be noted that Kuhn uses the term "disaster" in 1970, when his historiographical scheme has already become famous and his thesis on the scientific revolutions has essentially taken hold. Kuhn dares to judge negatively his teacher because believes that his own interpretation, based on a general "mechanical" explicative scheme, is efficient in every case, either textual or empirical of history of science. And the lack of accuracy of its single fundamental concepts, of which he is however conscious ${ }^{14}$, only appears to him as a secondary problem. However, this very unsolved problem will be the obstacle for its success in the case of the birth of quanta, as we will see thereafter.

\section{The Scientific Origin of the Second Kuhn's Historiographic Paradigm: BBT and Thermodynamics}

But if we have to use the term "disaster", we must rather say that Kuhn brought to a disaster his historiographic scheme when, in 1978, he applied it to study the birth of the quantum theory (Kuhn, 1978) (hereafter BBT); indeed, there he renounced to make use of the notion of "paradigm" as well as all other notions of his interpretative scheme.

Let us now cursorily recall the central thesis of BBT: Planck, when derived the black-body formula, and even when presented it in 1900, was unaware to be introducing quanta. According to Kuhn, in such a derivation Planck made use of a set of mathematical concepts inherited from Boltzmann, who exclusively had used them in his book Vorlesungen über Gastheorie. Among these concepts there is the partition of a continuum in a number of discrete cells; this operation allowed Boltzmann to calculate, through combinatorial techniques, entropy as a probabilistic notion. Kuhn maintained that such an essentially discrete partition of a continuum space was considered as a mere artifact of mathematical nature, applied by Planck to the energies of a resonator; hence, Kuhn denies that Planck introduced the idea of a physical "quantization". The required recognition of the physical nature of the quanta, lacking in Planck, was accomplished some years later by Einstein when, in order to fit Planck's radiation theory, he emphasised the necessity of introducing a new hypothesis; i.e. the resonator energy assumes discrete values only, which are integer multiples of an essential elementary value of this physical quantity.

An analysis of BBT shows that there Kuhn gives a central role to individual scientists, rather than to a scientific community; moreover the main notions of Kuhn's analysis are the following ones: "heredity", "phase", "continuity", "group of concepts" and "break with the classical physics" (Kuhn, 1978: p. 140), whereas the notion of "scientific community" is disappeared, as well as the notions of "paradigm", "normal science", "revolution", and "incommensurability". In conclusion, in BBT nothing reminds us that its author is the same of SSR.

Therefore we add to Table 1 one more row for representing Kuhn's new historiography (Table 4):

Although the debate about BBT presented contrasting ideas suggested by several historians (Cerreta, 2002), it did not weaken the widespread persuasion on the validity of Kuhn's general scheme, previously presented in SSR, but only his main results. This fact adds more evidence for the paradigmatic value of the historiographic

Table 4. Addition of kuhn's second historiographic attitude to Table 1.

\begin{tabular}{cccc}
\hline $\begin{array}{c}\text { HISTORIOGRAPHIC } \\
\text { SCHOOL }\end{array}$ & $\begin{array}{c}\text { CONCEPTION OF HISTORY } \\
\text { OF SCIENCE }\end{array}$ & $\begin{array}{c}\text { PICTURE OF BOTH SCIENCE } \\
\text { AND SCIENTISTS }\end{array}$ & HISTORIANS’ TASK \\
KUHN (1978) & Temporal narration of historical \\
events & $\begin{array}{c}\text { Individual scientists; } \\
\text { heredity, group of concepts, } \\
\text { phases, continuity, break with } \\
\text { the Classical Physics }\end{array}$ & $\begin{array}{c}\text { Recognition of the different } \\
\text { phases involved inside the case } \\
\text { study at issue }\end{array}$
\end{tabular}

$\overline{{ }^{14}(\text { Kuhn, 1970: pp.231-78; Kuhn, 1974: pp. 459-482) }}$. 
scheme presented by SSR; that is, historians gave philosophical validity to it by disregarding its effective applicability to further cases-studies independently from its applicability to specific case-studies.

\section{The Revolution in Kuhn's Historiographic Scheme}

Now we will interpret the lack of SSR's historiographic notions in BBT, by investigating his way of thinking through the same SSR basic notions. Kuhn had to apply to BBT his historiographic scheme since it was presented by him as a historiographic paradigm. We interpret his missed application of it in BBT as a failure; and hence as an anomaly for this historiographic paradigm presented in SSR. According to the historical dynamics presented by SSR, this anomaly leads to introduce a new historiographic paradigm. Indeed, Kuhn's change from a kind of highly interpretative categories to a kind of apparently only narrative categories well represents the Kuhn's move from his previous historiographic paradigm to a new one; in other words, what we can call his historiographic revolution.

Let's remark that the interpretative scheme elicited by Kuhn from Newtonian Mechanics is based on a discontinuous change ${ }^{15}$, occurring through two incommensurable kinematics states ("normal science" and "revolution"); instead the new interpretative scheme sees the history as changing continuously, though according to some different phases. Kuhn begins his narrative with "the classic phase", whose he recognises a precise group of probabilistic concepts pertaining to Boltzmann's theory of gases; these concepts have been introduced by Boltzmann in the fall of 1877 and kept until $1896^{16}$. Then Kuhn recognises this group of concepts inside Planck's derivation of the black body distribution law during the 1900-01 winter ${ }^{17}$. Finally, he describes the "emergency of the quantum discontinuity", but some years after and through Einstein. There, Einstein is described as both a careful reader of Planck's results on distribution law and the developer of an independent way to announce the birth of quanta, as it results from the famous 1905 and 1906 papers on light particles ${ }^{18}$.

Therefore, the traditional disrupting role, usually attributed to Planck inside the sequence of the historical events concerning the birth of quanta, in Kuhn's picture become a central role, but played only in an unaware way. Maybe, Kuhn's vision was influenced by Einstein's words: "Planck's theory uses implicitly [but only implicitly] the light quantum hypotesis"19. In order to control this Einstein's thesis Kuhn had to analyse Planck's book Lectures on the theory of thermal radiation (Planck, 1906), published in 1906. In this book, according to Kuhn, Planck exposes his theory in a parallel way with respect to his previous versions; this conceptual continuity proves that he, meanwhile, had not become more aware of the disruptive novelty of the quantization. If he had been aware of it, says moreover Kuhn, the sole hypothesis of quanta should have required a new base for his work.

Thus this Kuhn's picture does not show any interruption of the sequence of the events until Einstein's conclusions. In fact, it shows that in 1904 Einstein himself, reading Planck's writings as previously mentioned, even quotes the latter's definition of entropy and observes that none of Planck's first readers saw any quantization, notwithstanding the individual perceptions of the quantum evidence by Lorentz and Ehrenfest.

Although Kuhn is able to bring this "non standard" evidence back among the "normal" positions of other readers, he must admit that the two scientists (or at least one of them) had seen in Planck's articles the "substance”, we could say, of quantization ${ }^{20}$. In this picture, according to Kuhn, Planck plays both a conscious role of a classic scientist and an unaware role of a quantum scientist.

It seems that Kuhn is now trying to present the facts of the scientific activity of the time he is studying in a similar way to how physicists describe, in a Clapeyron's plane, the phases of the state of a thermodynamic system changing between its liquid phase and its gaseous phase. Let's then imagine a Clapeyron's plane as an historiographic area (Grattan-Guinness, 1990), i.e. as a region in which we represent the "scientific activity" of the previous system as a line composed by successive dots—each one representing a central idea occurring in papers and books of this time- - . As a whole, this line links two dots: the initial one, i.e. the partition of continuum in a number of discrete cells performed by Boltzmann in Vorlesungen über Gastheorie, and the final one, i.e. Ein-

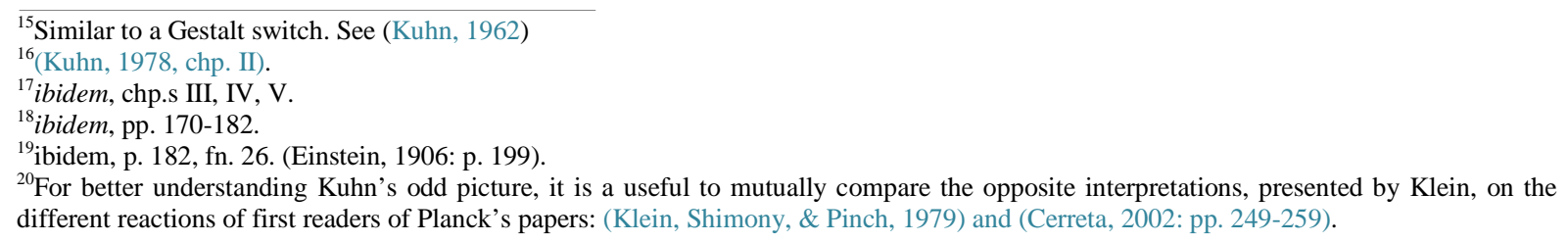


stein's hypothesis of the quantum. We can call "Boltzmann phase" the area (the liquid phase) of the plane where the initial dot is located, and "Einstein phase" the area (the gas phase) of the final dot of the thermodynamic system.

Kuhn describes the historical events as if the "scientific activity" began by Boltzmann, continued through Planck's deduction of the black-body law and arrived till up to Einstein's recognition of quanta. Let's remember here that this Boltzmann's activity is essentially based on the use of finite quantities for mathematical purpose. Under this light, the unaware role attributed to Planck may be interpreted as the critical point in which both liquid and gas coexist. We may consider this point as marking a metamorphosis of Boltzmann's finitistic idea (liquid phase) going in Einstein's quantistic idea (gas phase), although the metaphor inverts the roles of the discrete and the continuum (Table 5). In this way, all the events considered by Kuhn's narration take place in a continuous succession of stages which, even though they trespass the critical point severing classical physics from quantum physics, do not play the role of an anomaly, and hence do not imply a conflict between the two respective paradigms either.

This interpretation gives more evidence that it is possible to describe the historical events through a scheme of notions which are extracted from a scientific theory and then are translated in historical terms; the scheme of BBT, contrarily to the mechanistic one of SSR, comes from Thermodynamics.

In order to better understand in which way Kuhn's historical notions evolved in his mind, we analyse his historical studies between 1962 and 1978. In one of these studies we find out some interesting considerations ${ }^{21}$. (Kuhn, 1977) Kuhn recognizes two separate traditions in the development of sciences: the tradition of Classical sciences and the tradition of Baconian ones. Since along some centuries of science development their mutual contrast has never been completely conciliated-let us recall the persisting fundamental role of phenomenological thermodynamics played in e.g. Einstein's thought-Kuhn actually suggests a real fracture in the scientific thought; this fracture, Kuhn says, is deeply rooted in the human mind ${ }^{22}$. By assuming this Kuhn's tenet, then the two historiographic schemes illustrated above correspond to these two conflicting traditions. According to this point of view, we can see the passage of Kuhn from the mechanistic scheme to the thermodynamic one likely as the transition from his "classical" historiography to a "Bacon-like" one (again with an inversion, here in the temporal succession).

This intellectual passage of Kuhn's mind can be summarized by the following Table 6 .

\section{A Further Historiographic Revolution in Kuhn's Mind}

But this historiographic revolution was not Kuhn's last one. In fact, in the final period period of his life, Kuhn

Table 5. How the Notion of quanta emerged from an intellectual process similar to a phase transition.

\begin{tabular}{|c|c|c|c|}
\hline & Liquid phase & The critical point & Gas phase \\
\hline Kuhn's Historiographic Interpretation: & Boltzmann’s work & Planck’s Black Body law & $\begin{array}{c}\text { Einstein's paper } \\
\text { on quanta }\end{array}$ \\
\hline $\begin{array}{l}\text { A "phase transition" of the idea of a number } \\
\text { of discrete cells; it originates in the framework } \\
\text { of the continuum and then it is } \\
\text { applied to a discrete reality }\end{array}$ & $\begin{array}{l}\text { Boltzmann's partition } \\
\text { of the continuum in a } \\
\text { number of finite cells }\end{array}$ & $\begin{array}{l}\text { Boltzmann's finitistic idea is } \\
\text { used by Planck, being unaware } \\
\text { of the new physical reality }\end{array}$ & $\begin{array}{c}\text { Einstein's evidence } \\
\text { for quanta }\end{array}$ \\
\hline
\end{tabular}

Table 6. Change in Kuhn’s historiographic paradigms.

\begin{tabular}{ccc}
\hline & Historiographic scheme & Thought tradition from which he derives the scheme \\
\hline KUHN 1962 & Mechanics & Classical \\
KUHN 1978 & Thermodynamics & Baconian \\
\end{tabular}

\footnotetext{
${ }^{21}$ (Kuhn, 1977: pp. 31-65).
}

${ }^{22}$ ibidem p. 64. 
critically revisited his philosophical activity, starting from the surprising success of the SSR. He admitted that he had "left over" many philosophical problems arisen from this activity ${ }^{23}$ (Kuhn, 2000). After SSR, at the end of the Sixties, let's remember it, he had already given over the "paradigm" concept, by announcing to prefer the "disciplinary matrix" concept; which, however, was not less criticised than the former one.

Now he tries to recollect the philosophical ideas of his historiographic origins; he renews the analogy between the biological Darwinian evolution and the scientific development presented in the last pages of SSR. But two are the original concepts to which he does not want to renounce: the possibility of a general theory of the historical evolution of science and the notion of incommensurability ${ }^{24}$ (Drago, 1987).

Therefore, Kuhn plans to write a new book, taking as a historiographic scheme the speciation of the living beings, in order to interpret the successive branching of the scientific tree in several disciplines. This historiographic scheme is doubtless of a very general importance, although, as he writes, only sketched (Kuhn, 2000).

Let's notice that he speaks explicitly about the connection we pointed out above, i.e. between a science theory and the historical categories which underlay his thought. At the end, he recognises a conceptual correspondence between the scientific ideas and the interpretations of the history of scientific facts, stressing the "parallelisms between the biological evolution and the scientific advancement” (Kuhn, 2000: p. 97). But he apparently ignores that this type of correspondence has structured his work from the very beginning. According to the method previously illustrated we see that the distinction between the species substitutes the previous notion of incommensurability; by keeping in mind this fundamental idea, each successive speciation works as a revolution in the previous historiographic sense, the biological niches playing the role of the scientific communities; moreover the languages of the biological niches, in our opinion, have the same function of the paradigms, but their mutual contrast occurs not only, as in SSR, in a temporal succession but even in a parallel-way.

Nevertheless, Kuhn thinks as insufficient for his historiographic purposes the only biological evolution scheme; he adds to it more specifications, which he founds in Kant's philosophy; it would be too long to illustrate them here (Kuhn, 2000: pp. 103-104). His resulting scheme is "Kantian”, owing to the fact that the lexicon of the niches works like the "a priori" Kant's categories of our mind; it supplies the "preconditions of possible experiences” (Kuhn, 2000: p. 104). Kuhn baptizes this scheme as a "Kantian-Postdarwinian” one. However, these categories are not fixed; they change along the evolution of the lexicon itself. What doesn't change, according to Kuhn, is something corresponding to the Kantian "Thing in itself" (Kuhn, 2000: p. 104) (Ding an sich), that he describes through these words: "underlying all these processes of differentiation and change, there must ...be something permanent, fixed, and stable... but it is ineffable, indescribable, unquestionable” (Kuhn, 2000: p.104).

In our opinion the lexicon, in Kuhn's purposes, should acquire the conceptual heredity of the paradigm, by offering to who wants to belong to a community its "a priori”, specific schemes. The changes of lexicon, instead, occur any time the community specializes itself further. It is well known that the categories of Kant's philosophy depend themselves from the Newtonian reference frame; hence Kuhn again introduces-in a surreptitious way-into the history of science what the science suggested to the philosophy of Kant space and time as categories. After his relying on Thermodynamics, Kuhn came back to Classical Sciences!

The scheme is "Postdarwinian" because it is analogous to that of the Darwinian evolution of the species, which —as Kuhn puts it—is similar to the evolution of science because is not oriented towards a final goal, but proceeds by branching from previous species.

Kuhn's set of concepts had the chance to become famous but not formally consistent, being never devoid of interpretative problems. Sketching an evolutionistic epistemology, he now tries to furnish a definitive and acceptable form for his system.

As a result, we add a new row to the previous Table 1 and Table 4:

${ }^{24}$ One of us suggested a general interpretation of history of science according to two basic dichotomies, whose philosophical origin may be traced back to Leibniz's two labyrinths of human mind and to the two couple of Kant's antinomies. (Drago, 1987: pp. 159-162) "I quattro modelli della realtà fisica”, Epistemologia, 13 (1990), 303-324. Out the four couple of possible choices on these dichotomies, a couple whose cultural influence is dominant in the scientific milieu is called a paradigm. Newtonian theory was paradigm because hits choices were for the actual infinity and the deductive organization of the theory. Also Darwinian theory share the same choices: the actual infinite time of all generations of biological life and the deductive theory form the principle of natural selection. In fact, also this theory was a paradigm in biological sciences and beyond in the cultural milieu. In this framework, Kuhn's choices in historiography appear as very consistent in choosing the paradigmatic theories-i.e. the Newtonian one and the Darwinian one-. He was deceived by the quanta revolution because he was inadvertent that the quanta birth occurred against the dominant paradigm, and hence in this case his historiography implicitly referred to thermodynamics, the rival theory of Newtonian mechanics.
} 


\begin{tabular}{cccc}
\hline HISTORIOGRAPHIC SCHOOL & $\begin{array}{c}\text { CONCEPTION OF HISTORY } \\
\text { OF SCIENCE }\end{array}$ & $\begin{array}{c}\text { PICTURE OF SCIENCE (AND } \\
\text { OF SCIENTISTS) }\end{array}$ & HISTORIANS' TASK \\
KUHN (1990) & $\begin{array}{c}\text { History of science as the } \\
\text { Darwinian biological } \\
\text { speciation, associated to both } \\
\text { Kant's “a priori" categories and } \\
\text { Kant's "thing in itself” }\end{array}$ & $\begin{array}{c}\text { Sectors of Science similar to } \\
\text { branches of biological tree. } \\
\text { The revolutionary changes in } \\
\text { sciences correspond to the } \\
\text { increases in biological speciation }\end{array}$ & $\begin{array}{c}\text { Recognition of lexicon and } \\
\text { taxonomic changes inside } \\
\text { the scientific communities. }\end{array}$ \\
\hline
\end{tabular}

As well as to the previous Table 5:

\begin{tabular}{ccc} 
& HISTORIOGRAPHIC SCHEME & THOUGHT TRADITION FROM WHICH HE DERIVES THE SCHEME \\
\hline KUHN 1990 & Darwin's Biological Evolution & Baconian Sciences \& Kantian Philosophy \\
\hline
\end{tabular}

Unfortunately, Kuhn's planned book never appeared.

Nevertheless, we can state that his final philosophical design makes apparent that his persistent method was to take as basic a particular scientific theory from which he extracted a scheme of notions to be translated in historical terms through which to interpret specific case-studies of the history of science. In other terms, Brush's attitude, already quoted, was generalised by Kuhn in an opportunistic way according to the subject of his historiography.

\section{References}

Brush, S. G. (1983). Statistical Physics and Atomic Theory of Matter. Princeton: Princeton U.P., 21.

Caneva, K. L. (2000). Possible Kuhns in the History of Science. Anomalies and Incommensurable Paradigms. Studies in Histyory and Philosophy of Science, 31, 87-124.

Cassirer, E. (1906). Das Erkenntnisproblem in der Philosophie und Wissenschaft der neueren Zeit. Berlin: B. Cassirer.

Cerreta, P. (1994a). II confronto tra le storiografie di Kuhn e di Koyré. In C. Vinti (Ed.), Alexander Koyré. L'avventura Intellettuale (pp. 647-657). Napoli: Edizioni Scientifiche Italiane.

Cerreta, P. (1994b). Kuhn’s Analysis of History of Black Body: From “Paradigm” to “Groups of Concepts”. In C. Cellucci et al. (Eds.), Atti del Congresso Logica e filosofia della scienza: Problemi e prospettive. Lucca: Edizioni ETS.

Cerreta, P. (1995a). Kuhn’s Interpretation of Boltzmann’s Statistic Heredity in Planck. In G. Garola, \& A. Rossi (Eds.), The Foundations of Quantum Mechanics. Historical Analysis and Open Questions (pp. 139-146). Lecce: Kluwer Academic Publishers.

Cerreta, P. (1995b). Historiographical Paradigms: Koyré, Kuhn and Beyond. In L. Kovacs, (Ed.), History of Science in Teaching Physics (pp. 68-73). Szombathely: Studia Physica Savariensia.

Cerreta, P. (2002). The Birth of Quanta: A Historiographic Confrontation. In H. Kragh, G. Vanpaemel, \& P. Marage (Eds.), Proceedings of the XXth International Congress of History of Science, Vol XIV, History of Modern Physics (pp. 249-259). Turnhout: Brepols.

Cerreta, P., \& Drago, A. (1991). Matematica e conoscenza storica. La interpretazione di Kuhn della storia della scienza. In L. Magnani (Ed.), Conoscenza e Matematica. Milano: Marcos y Marcos.

Cerreta, P., \& Drago, A. (2004). II programma storiografico di Kuhn caratterizzato secondo due programmi di ricerca sui fondamenti della scienza. In P. Tucci, A. Garuccio, \& M. Nigro (Eds.), Atti del XXIII Congresso nazionale di Storia della fisica e dell'astronomia (pp. 120-130). Bari: Progedit.

Chenoweth, E., \& Stephen, M. (2011). Why Civil Resistance Works. Columbia: Columbia U.P.

Corry, L. (1993). Kuhnian Issues, Scientific Revolutions and the History of Mathematics. Studies in History and Philosophy of Science, 24, 95-101. http://dx.doi.org/10.1016/0039-3681(93)90026-G

De Regt, H. (1996). Philosophy of the Kinetic Theory of Gases. British Journal for the Philosophy of Science, 47, 31-62. http://dx.doi.org/10.1093/bjps/47.1.31

Drago, A. (1987). An Effective Definition of Incommensurability. VIII Congress on Logic, Methodology and Phil. Sci., 4, 159-162.

Drago, A. (1994). Interpretazione delle frasi caratteristiche di Koyré e loro estensione alla storia della fisica dell'ottocento. In C. Vinti (Ed.), Alexandre Koyré. L’avventura Intellettuale (pp. 657-691). Napoli: ESI. 
Drago, A. (1996). Caratterizzazione strutturale delle storiografie della scienza di Koyré, Kuhn e seguenti. In A. Rossi (Ed.), Atti XIV e XV Congr. Naz. St. Fisica (pp. 159-167). Lecce: Conte.

Drago, A. (2010). Le rivoluzioni non violente del secolo scorso. Roma: Nuova Cultura.

Drago, A. (2016). The Revolutionary Role Played by Koyré in the Historiography of Science. In R. Pisano (Ed.), Hypotheses and Perspectives within History and Philosophy of Science. Hommage to Alexandre Koyré 1964-2014. Berlin: Springer. (Forthcoming)

Einstein, A. (1906). Zur Theorie der Lichterzeugung und Lichtabsorbition. Annalen der Physik, 20, 199. http://dx.doi.org/10.1002/andp.19063250613

Gernand, H. W., \& Reedy, W. Y. (1986). Planck, Kuhn and Scientific Revolutions. Journal of the History of Ideas, 47, 469-485. http://dx.doi.org/10.2307/2709664

Grattan-Guinness, I. (1990). Convolutions in French Mathematics 1800-1840 (Vol. 1, p. 6). Berlin: Birkhauser.

Klein, M. J., Shimony, A., \& Pinch, T. J. (1979). Paradigm Lost? A Review Symposium. Isis, 70, 430-434.

Kokowski, M. (2006). A Meta-History of Science and Methodology of the History of Science Urgently Needed! The Global and the Local: The History of Science and the Cultural Integration of Europe. Proceedings of the 2nd ICESHS, Cracow, Poland, 6-9 September 2006, 856-863.

http://www.2iceshs.cyfronet.pl/2ICESHS Proceedings/Chapter 27/R-19 Kokowski.pdf

Koyré, A. (1966). Études Galiléennes (1939). Paris: Hermann.

Kuhn, T. S. (1957). The Copernican Revolution. Harvard: Harvard U.P.

Kuhn, T. S. (1962). The Structure of Scientific Revolutions. Chicago, IL: University of Chicago Press.

Kuhn, T. S. (1970a). Alexander Koyré and the History of Science. Encounter, XXXIV, 69.

Kuhn, T. S. (1970b). Reflections on My Critics. In I. Lakatos, \& A. Musgrave (Eds.), Criticism and the Growth of Knowledge (pp. 231-278). London: Cambridge University Press. http://dx.doi.org/10.1017/CBO9781139171434.011

Kuhn, T. S. (1970c). The Structure of Scientific Revolutions. 2nd ed., Chicago: University of Chicago Press, 1-3.

Kuhn, T. S. (1974). Second Thoughts on Paradigms. In F. Suppe (Ed.), The Structure of Scientific Theories (pp. 459-482). Urbana: University of Illinois Press.

Kuhn, T. S. (1977). Mathematical and Experimental Traditions in the Development of the Physical Sciences. The Essential Tension, op. cit., 31-65.

Kuhn, T. S. (1977). The Concept of Cause and the Development of Physics. In The Essential Tension (pp. 21-30). Chicago, IL: The University of Chicago.

Kuhn, T. S. (1978). Black Body Theory and the Quantum Discontinuity, 1894-1912. Oxford, New York: Clarendon Press.

Kuhn, T. S. (1980). The Halt and the Blind: Philosophy and History of Science. British Journal for the Philosophy of Science, 31, 181-192. http://dx.doi.org/10.1093/bjps/31.2.181

Kuhn, T. S. (1984). Revisiting Planck. Historical Studies in the Natural Sciences, 14, 231-252. http://dx.doi.org/10.2307/27757534

Kuhn, T. S. (2000). The Road since Structure. In The Road since Structure (pp. 90-104). Chicago, IL: Chicago University Press.

Larvor, B. (2003). Why Did Kuhn's Structure of Scientific Revolution Cause a Fuss? Studies in History and Philosophy of Science, 34, 369-390.

Mastermann, M. (1970). The Nature of Paradigm. In I. Lakatos, \& A. Musgrave, Eds., Criticism and the Growth of Knowledge (pp. 59-89). Cambridge: Cambridge University Press.

Moore, P. (1982). Revolution in Science: 20 Years on. New Scientist, 95, 372; New York Times Book Review, 4 October 1992.

Planck, M. (1906). Vorlesungen über die Theorie der Warmestrahlung. Annalen der Physik, 30, 211.

Wray, K. B. (2007). Kuhnian Revolutions Revisited. Synthèse, 158, 61-73. 


\section{Submit or recommend next manuscript to SCIRP and we will provide best service for you:}

Accepting pre-submission inquiries through Email, Facebook, Linkedin, Twitter, etc A wide selection of journals (inclusive of 9 subjects, more than 200 journals)

Providing a 24-hour high-quality service

User-friendly online submission system

Fair and swift peer-review system

Efficient typesetting and proofreading procedure

Display of the result of downloads and visits, as well as the number of cited articles

Maximum dissemination of your research work

Submit your manuscript at: http://papersubmission.scirp.org/ 